\title{
Problems and Countermeasures in the Construction of Regional Agricultural Products E-Commerce Platform in Second- and Third-Tier Cities
}

\author{
Ping Gong \\ Heilongjiang BayiAgricultural University, Daqing, Heilongjiang, 163319, China
}

Keywords: Regional e-commerce platform; Agricultural products; Online and offline integration

\begin{abstract}
The Internet has subverted the traditional business model, and all walks of life are exploring the mode, channel and path of integration with the Internet. It is a major issue related to the national economy and people's livelihood how to exert the openness and fairness of the Internet and to promote the fuller connection between farmers and the market, farmers and consumers. It is essential to enable consumers to get green agricultural products and enable farmers to get higher income, ultimately achieving win-win results in many ways. Based on the in-depth research on the construction of e-commerce platform for agricultural products and the basic situation of online and offline coordinated development, it is proposed to build an ecosystem of e-commerce platform for agricultural products in line with local development and characteristics, which is conducive to the integration of agricultural and commercial enterprise resources. It is also helpful for the local economic development, the improvement and optimization of industrial structure, and the solution of employment problems.
\end{abstract}

\section{Introduction}

The Internet has subverted the traditional business model, and all walks of life are exploring the mode, channel and path of integration with the Internet. The Internet economy has injected new vitality into the practice of agricultural products transportation and marketing. It spans the constraints of time and space between the supply and demand of agricultural products, increases the categories of agricultural products transactions, and reduces the links and time of agricultural products transportation and marketing transactions[1]. However, the e-commerce of agricultural products started late and the regional development is unbalanced. The agricultural products in China, especially in the second and third tier cities, need to be deeply integrated with the Internet to improve the production efficiency of the industry chain, update the sales channels, and open up the capital chain and logistics chain. 


\section{Regional Agricultural Products E-Commerce Platform Mode and Development Status}

\subsection{Regional agricultural products e-commerce platform mode}

According to different subjects, the development mode of agricultural e-commerce can be divided into two types: Comprehensive Cross-border E-commerce Mode and Vertical E-commerce Platform Mode of agricultural products in the whole industrial chain[2].

The Comprehensive Cross-border E-commerce Mode is mainly based on Tmall, Taobao and Jingdong. The first feature of this kind of platform is that the platform itself already has a lot of network flow, which is not a problem for this kind of platform, but the current consumer awareness of online purchase of agricultural products is not very strong compared with clothing, electronic products, etc..Therefore, it is necessary to cultivate the consumer awareness of online purchase of agricultural products slowly. Tmall's "miaoxiansheng", Taobao's "agriculture promotion and poverty alleviation" and Jingdong's "fresh" channels all have special channels for the sale of agricultural products, which is one of the features not found in other categories of products. It can be seen that, in order to cultivate consumers' awareness of online purchase of agricultural products, all major e-commerce platforms have made great efforts in web page design. The second characteristic of the Cross-border Mode of Comprehensive E-commerce is that the platform itself has brand advantage, which is also conducive to the promotion and development of agricultural products brand.

The representative platforms of the Vertical E-commerce Platform Model of Agricultural Products in the whole industrial chain include COFCO online shopping (womai.com), Tootoo Industry and Trade Association (www.tootoo.cn), Motion Optimization(sfbest.com) and Original Life(benlai.com). Such platforms are characterized by online food shopping malls, agricultural products procurement, online sales, logistics and distribution. Some platforms are committed to finding the best agricultural product procurement and integrating the high-quality supply resources of the global food industry. Others have their own farms and are committed to controlling the food quality of agricultural products from the source. The characteristics of the platforms are as follows: first, they are basically located in the first-tier cities such as Beijing and Shanghai, with the middle and high-end consumers in Beijing and Shanghai as the main target group, so the product supply is basically high-quality healthy agricultural products or organic food, and the commodity price belongs to skimming pricing. Second, they have built their own proprietary cold chain storage and distribution logistics system to ensure that fresh products can be delivered to consumers in time.

\subsection{Basic situation of regional agricultural products e-commerce platform construction}

At present, the development of e-commerce in the second and third-tier cities mainly relies on the e-commerce industrial parks built in each district and county, cultivating and guiding the development of e-commerce enterprises and platforms. In the market economy environment, the highest goal of enterprises is to pursue the maximization of interests and consumers' utility[3].Through training and leading enterprises, many traditional business enterprises also turn to online and offline integration mode, realizing the rapid development of e-commerce.

The online sales of goods in the second and third tier cities mainly rely on the third-party e-commerce platforms such as Jingdong, Taobao, Tmall, etc. The owners build online stores on Taobao, Tmall and other comprehensive websites, and build local characteristic pavilions in Jingdong Mall. The popularity and market share of the goods are constantly expanded, so that the people across the country gradually understand the local goods.

Most of the second and third-tier cities, especially the third-tier cities, do not have mature regional e-commerce platforms built by themselves at present. Some platforms only provide 
corresponding information rather than network sales. Some small-scale e-commerce start-ups that carry out network sales currently have small market scale, small market share and low popularity. Generally speaking, the construction and development of regional e-commerce platform in the second and third tier cities is relatively backward.

\section{Problems in the Construction of Regional E-Commerce Platform for Agricultural Products}

\subsection{Lack of understanding of e-commerce management concept of agricultural products}

The convenience brought by staying indoors and the development of express industry make consumers sticky to online shopping. Therefore, it is of great urgency for agricultural product operators to carry out e-commerce business. When communicating with the operators who intend to enter the e-commerce market, they are often confused about what preparation and conditions are needed for the e-commerce operation. They don't know how to open a store, and they are more concerned about issues such as the release of goods, web design, etc., while they hardly talk about the later operation. However, the e-commerce management of agricultural products is not only to build a website or put their own products on a third-party platform. The later operation and management arefar more important and complex than the establishment of a website. Because the competition degree of online operation is much greater than that of physical operation, consumers have more choices. How to let consumers see the products of operators in the vast ocean of commodities is the first problem we should consider as the operators of agricultural products e-commerce.

\subsection{Lack of talents in e-commerce of agricultural products}

There is no doubt that the lack of agricultural e-commerce talents is the most important problem in the construction of most regional agricultural e-commerce platforms. Most of the agricultural e-commerce talents are concentrated in the cities with relatively developed e-commerce, such as Beijing, Guangzhou and Hangzhou. On the one hand, the lack of agricultural e-commerce talents makes the initial construction of online shopping platform more difficult, and the cost is higher, which makes many self-employed operators who intend to enter the third-party platform flinch; on the other hand, due to the lack of agricultural e-commerce platform talents, many operators who intend to carry out agricultural e-commerce are keen to the construction of e-commerce website. However, because of the follow-up poor management, they fail to run it very well. Third, the lack of talents in e-commerce of agricultural products makes e-commerce of agricultural products lack of atmosphere. Without the guidance of advanced people, the operators cannot see the huge potential of online sales, but only see the corresponding risks of online sales, so they are deterred and stopped.

\subsection{Inadequate infrastructure such as warehousing and logistics}

Most of the vertical e-commerce platforms for agricultural products, such as Beijing and Shanghai, have their own warehousing and logistics facilities. Tootoo Industry and Trade Association has built a modern warehousing and distribution logistics center with an area of nearly 10000 square meters, which integrates refrigeration, freezer and processing workshop. It adopts the distribution operation mode of cold chain logistics to deliver fresh food to consumers accurately. By virtue of its unique advantages, Motion Optimization(sfbest.com) ensures that fresh food can be delivered to consumers in time. Original Life(benlai.com) ensures that the nutrition and moisture of all food materials are only lost to a minimum. It is equipped with refrigerated warehouses $\left(0-4{ }^{\circ} \mathrm{C}\right)$ and freezers $\left(18{ }^{\circ} \mathrm{C}\right)$ 
that meet professional standards to store separately according to the unique fresh-keeping requirements of each commodityand provides cold chain distribution for more than 8 hours. The lack of a modern storage and distribution logistics center cannot guarantee that food can be stored fresh and cold chain logistics after picking. The cost of cold chain transportation is also $40-60 \%$ higher than that of ordinary vehicles[4]. Most of the arrived goods or the goods sent from them need to be transferred, which undoubtedly increases the cost and time of transportation, while for agricultural products, especially fresh products, the requirements for transportation time are undoubtedly strict.

\subsection{Simple and extensive website design}

(1) From the perspective of design, many online stores opened on third-party platforms such as Taobao and Jingdong can be seen that their web design is relatively simple. The website architecture and website positioning are not prominent enough. Many functional modules are not perfect. The product update is slow or not updated, and the details page setting is extremely simple, which does not highlight the characteristics of the product. The web page is just the stacking of some pictures. They can't catch the eyes of consumers at all. Many self-built websites always want to take many functions into account. For example, a website wants to be a comprehensive platform including city introduction, government publicity, information consultation and online shopping, which are not convenient for online shopping. A website should not have so many functions but should "specialize in technology".

(2) From a technical point of view, many of our own shopping websites or information platforms are slow to respond. When the consumers click into the website, the web page is slow to display, which also forms a sharp contrast with the third-party platform, greatly reducing the purchase intention of consumers.

(3) From the perspective of service, a lot of goods, such as the milk powder in Jingdong Pavilion is in the state of being out of stock, while the milk powder is on sale in other cities' Pavilion. In many online stores on the third-party platform, it is slow to communicate with the shopkeeper about relevant information, which cannot meet the consumer's demand for online purchase.

\section{Suggestions on the Construction of E-Commerce Platform for Agricultural Products and Online and Offline Integration}

The online and offline integration of agricultural products includes Online transaction - Offline consumption experience mode, Offline marketing - Online transaction mode, Online operation Online transaction - Offline consumption experience mode, Online transaction or marketing Offline consumption experience - Online consumption experience sales mode[5]. E-commerce of agricultural products can take one or several of the above-mentioned ways according to the situation. For example, many branches of Dazhuangyuan Meat Stores,specializing in selling beef and mutton, will establish their own Wechat group, which is carried out through Online marketing - Offline consumption experience. This is a primary way of online and offline integration, but one of the effective ways. No matter which way we take, we should strengthen the construction from the following aspects to form an effective online and offline ecosystem.

\subsection{Strengthen the standardization construction of agricultural products on e-commerce platform}

Tootoo Industry and Trade Association, COFCO's online shopping website and the Original Life website all attach great importance to the initial purchase of products. The quality of agricultural 
products is the source of marketing, and food safety is the top priority of consumers in the current environment. Many second- and third- tier cities have their own characteristic products, but the products are not standardized enough, because there is no quality supervision system or quality traceability system that can be reflected to consumers. The nature between e-commerce sales and wholesale \& retail is totally different. We should show consumers the standardization and professionalism of our products at the source, such as land, products cultivating and packaging. We also haveto improve the standardization of products or the standardization and professionalism of external publicity. At the same time, the logistics operation standard system can be established, including the insurance technology and refrigeration and insulation technology standards for agricultural raw material collection, sorting, processing and packaging, cooling and freezing, cold storage and storage, packaging identification, cold storage and transportation, wholesale distribution, distribution and retail[6]. The quality of products is the basis of all marketing activities. Excellent product quality can generate the desire to buy again after consumers' purchasing, increase the reputation of products, improve the stickiness of consumers for products, and thus improve the brand dependence.

\subsection{Strengthen the specialized service of e-commerce platform for agricultural products}

It is difficult to achieve short-term results simply by relying on ordinary farmers and traditional operators to access the Internet to carry out e-commerce services. Many small and medium-sized operators have a strong sense of operating online stores. However, the reason why they fail is that they were unable to understand the network operation at the beginning of the establishment of the store and did not predict the costs and manpower needed for the operation and publicity of online stores in the later period. Therefore, the government should strengthen the specialized service of e-commerce platform for agricultural products.

First of all, carry out a series of training related to the construction, operation and promotion of e-commerce platform for farmers and traditional small and medium-sized enterprises, so that farmers and traditional small and medium-sized enterprises can understand a series of related procedures after the website design, as well as the possible costs and talents needed at the beginning of their access to the Internet.

Secondly, after the establishment of the network, there should be enterprises or individuals which can provide specialized services for network operation and later promotion to help small and medium-sized enterprises find places to consult and guarantee subsequent operation. Many small and medium-sized e-businesses need this kind of service through large companies in first- tier cities. Some e-business owners look for different people to beautify their pictures or photos and modify the website text, which increases the time cost to operate, and it is not very convenient to communicate with different people. The website design is not professional, so we urgently need talents in e-business operation to provide professional services which small and medium-sized e-commerce need.

Finally, an e-commerce service team can be set up to provide specialized services for consumers of small and medium-sized e-commerce. Many small and medium-sized e-commerce think that only the product can be released to the platform, and the lack of service or after-sales service in the later period is not timely, which leads to the loss of many customers, and the lack of customers makes small and medium-sized e-commerce enterprises not willing to invest too much energy in e-commerce, forming a vicious circle. Therefore, we can form a professional e-commerce service team to provide services for small and medium-sized e-commerce in the early stage, and answer questions of consumers in the sale and after-sale for small and medium-sized e-commerce, which 
are not only professional but also cost-effective, so that small and medium-sized e-commerce can develop faster.

\subsection{Strengthen the brand building of agricultural products on e-commerce platform}

Taking Northeast China as an example, when communicating with farmers and agricultural products management enterprises, especially rice manufacturers, we can find that their rice quality is very good, but many rice brands are not known by Chinese people, which is very passive in network sales. We should establish our own agricultural products brands and agricultural products e-commerce brands.

On the basis of product standardization, excellent designers can be hired to design product packaging for us in terms of branding, attract consumers' attention from packaging, improve consumers' purchase desire, and then carry out brand promotion and communication through various ways. E-commerce has a variety of ways. In addition to existing self-built website marketing and third-party trading platform marketing, there are also Search Engine promotion, online platform advertising, email advertising, newsgroup tools, microblog advertising and even viral advertising and other online advertising means. The main purpose of these means is to use the rapid development of network technology to improve the click- through rate and visit volume of the website. In short, the publicity and promotion should be strengthened to raise products popularity.

\subsection{Strengthen the logistics construction of agricultural products on e-commerce platform}

Warehouse and logistics is a big short board for the development of e-commerce. Taking rice products as an example, it is found that sometimes the logistics cost is greater than the rice cost itself in e-commerce operation, which is very unfavorable for the sale of heavy goods such as rice. The development of e-commerce is bound to be accompanied by the improvement of urban infrastructure and other functions. Therefore, it is the necessary for us to strengthen the construction of warehousing and logistics in the suburbs. With the development of e-commerce, consumers have higher and higher requirements for the freshness and logistics speed of agricultural products. Warehousing can ensure the quality and freshness of agricultural products. Logistics can make goods reach consumers' hands quickly and can solve the last- kilometer- problem in rural suburbs. Therefore, it is necessary to build its own logistics distribution system to make products reach consumers' hands in a good and fast way.

\section{Conclusion}

At present, there is no mature regional e-commerce platform built by the second and third-tier cities. Some platforms only provide corresponding information rather than network sales. Some small-scale e-commerce start-ups that carry out network sales have small market scale, small market share and low popularity. Generally speaking, the construction and development of regional e-commerce platform is relatively backward. In addition, there are some problems, such as lack of understanding of e-commerce management concept of agricultural products, lack of talents in e-commerce management of agricultural products, imperfect infrastructure such as warehousing and logistics, simple and extensive website design, etc. Therefore, To build a good online and offline ecosystem, we should strengthen the standardization construction of agricultural products of e-commerce platform, strengthen the professional service of agricultural products e-commerce platform, strengthen the brand construction of agricultural products of e-commerce platform, and strengthen the agricultural products of e-commerce platform. 


\section{ACKNOWLEDGEMENTS}

This paper is a periodical research result of "Heilongjiang Bayi Agricultural University Support Program for San Heng San Zong” (No. TDJH201811).

\section{Reference}

[1] Jihong Ge. Agricultural products transportation and marketing reengineering in the Internet Era -- an example from "Chu Cheng". Agricultural economic problems, 2016(10):51-59.

[2] Guoying Li. The deconstruction of China's modern agricultural industry chain and business model under the background of Interne. Rural economy, 2015(09):29-33.

[3]Xueli Yang, Ping Gong. The cultivation of consumption ecological view of urban residents from the perspective of ecological civilization construction. International Journal of Education and Econmics, 2019(3)301-304

[4] Jianxin Li. The main problems and Countermeasures in the development of e-commerce of fresh agricultural products. China's circulation economy, 2016(12):57-64.

[5] Ruiqiang Li. Research on online and offline integrated service mode of agricultural e-commerce platform in the era of "Internet". Agricultural economy,2016(11):120-122.

[6] Xuhui Wang, Qilin Zhang. Research on the circulation mode of agricultural products based on online and offline integration. Journal of Beijing University of Technology (SOCIAL SCIENCES), 2014(03):18-25. 